\title{
Purification of a Human Liver Cytochrome P-450 Immunochemically Related to Several Cytochromes P-450 Purified from Untreated Rats
}

\author{
Steven A. Wrighton, * Paul E. Thomas, ${ }^{\ddagger}$ Patricia Willis," Sarah L. Maines, ${ }^{\ddagger}$ \\ Paul B. Watkins, " Wayne Levin," and Philip S. Guzelian* \\ *Division of Clinical Toxicology and Environmental Medicine, Department of Medicine, Medical College of Virginia, \\ Richmond, Virginia 23298; and ${ }^{\ddagger}$ Laboratory of Experimental Carcinogenesis and Metabolism, \\ Roche Institute of Molecular Biology, Nutley, New Jersey 07110
}

\begin{abstract}
Among characterized forms of liver microsomal cytochromes $P-450$ in rats are four related isozymes (P-450f-i) notable for their lack of inducibility. Immunoblot analyses demonstrated that human livers microsomes contained several proteins related to these rat P-450s. A human liver P-450, termed HLx, was purified and found by immunochemical assays to resemble rat $\mathrm{P}-450 \mathrm{~g}$. Analysis of the $\mathrm{NH}_{2}$-terminal amino acid sequence of $\mathrm{HLx}$ indicates that it is related to rat $P-450 \mathrm{~s} f-i$ and human liver P-450MP. A monoclonal antibody was used to measure the amounts of HLx in 21 human liver specimens. No correlation between the levels of HLx protein in these specimens and the patients' environmental histories was observed. However, statistical analysis of the data suggests that the distribution of HLx is at least bimodal. We conclude that HLx is a member of a family of human liver $P-450$ s that resembles in its structure, and possibly in its distribution, several liver $P-450$ s found in other animals.
\end{abstract}

\section{Introduction}

The cytochromes P-450 in the endoplasmic reticulum of the hepatocyte represent an important biochemical locus for the biotransformation of chemicals. This superfamily of hemoproteins catalyzes the oxidative metabolism of an array of endogenous and exogenous lipophilic compounds $(1,2)$. The rates at which these substrates are oxidized and the nature of the metabolites produced depend at least to some extent on the concentrations of individual isozymes of cytochromes P-450. These enzyme concentrations are controlled by genetic factors $(3,4)$ and also by drugs, diet, and environmental agents $(1,2$, 5) that may increase or decrease specific cytochrome P-450 isozymes selectively.

Until recently, the types and amounts of cytochrome $P-450$ isozymes in the liver could be assessed only indirectly from measurements of the metabolism of prototype substrates

Address correspondence to Dr. Steven A. Wrighton, Department of Pharmacology and Toxicology, Medical College of Wisconsin, 8701 Watertown Plank Road, Milwaukee, WI 53226.

Dr. Watkin's current address is University of Michigan Medical Center, 6510D Medical Science Research Building 1, Ann Arbor, MI 48109.

Received for publication 26 November 1986 and in revised form 6 May 1987.

J. Clin. Invest.

(c) The American Society for Clinical Investigation, Inc. 0021-9738/87/10/1017/06 \$2.00

Volume 80, October 1987, 1017-1022 in vivo or by liver microsomes. However, advances in protein purification techniques, coupled with immunochemical methods including preparation of monospecific antibodies, has made it possible to purify more than 15 separate polypeptide forms of rat liver cytochrome P-450 (6) and to characterize their structure and regulation (6-8). This technology also offers an opportunity to critically assess the question of how relevant the abundant information about animal cytochromes $\mathrm{P}-450$ is to man. For example, we recently demonstrated that human liver contains HLp (9), a cytochrome P-450 that resembles rat liver cytochrome P-450p (10) in its immunochemical characteristics, its $\mathrm{NH}_{2}$-terminal amino acid sequence, its catalytic activities, and its apparent inducibility in man by glucocorticoids or macrolide antibodies (9). We have also purified from human liver two other novel cytochromes P-450: HLd, a cytochrome orthologous to the 3-methylcholanthrene-inducible $\mathrm{P}-450 \mathrm{~d}$ in the rat $(11)$, and $\mathrm{HLj}$, a cytochrome P-450 orthologous to rat cytochrome $\mathrm{P}-450 \mathrm{j}$ in being the major $N$-nitrosodimethylamine demethylase induced in humans drinking ethanol to excess or receiving isoniazid treatment (12).

In addition to such inducible forms of liver cytochrome $\mathrm{P}-450$, there is a group of immunochemically related cytochromes in rats $(13-16)$ and rabbits $(17,18)$ that comprise the bulk of cytochrome P-450 in untreated animals. It has been suggested that these cytochromes P-450, which are relatively refractory to induction by many xenobiotics, may be involved in pathways for metabolism of endogenous substrates at steps where modulation by environmental agents would be undesirable (19). To investigate the human representatives of this family, we purified a human liver cytochrome P-450 termed HLx. Through the use of immunochemical characterizations, we demonstrate that HLx is related to rat cytochromes P-450f-i. ${ }^{1}$ Finally, we show that, as with cytochrome $\mathrm{P}-450 \mathrm{~g}$ in outbred Long Evans rats (21) and in Sprague-Dawley rats (22), HLx does not appear to be inducible in man but rather exhibits a polymorphism, presumably under genetic control, in the level of its spontaneous expression.

\section{Methods}

Human liver specimens. Specimens were obtained at surgery in accordance with protocols approved by the Committee for the Conduct of Human Research at the Medical College of Virginia. All patients had normal transaminase and bilirubin levels and received atropine before

1. Cytochrome P-450k (PB-1[20]) is a fifth member of this family of immunochemically related proteins in the rat $(21)$. This protein, unlike cytochromes P-450f-i, is inducible by phenobarbital and shares $75 \%$ total sequence homology with cytochrome P-450f (20). 
general anesthesia, except patient 17 , who also received dexamethasone $5 \mathrm{~h}$ before surgery. Patient code numbers refer to individual liver samples. The patients' ages, genders, and medications are listed in Table I. Microsomes prepared by differential centrifugation (23) were stored as described previously under conditions in which the levels of cytochrome HLp (9) have remained stable for up to 2 yr. Protein concentrations of the microsomal samples were determined colorimetrically (24).

Purification of human liver cytochrome P-450 HLx. All steps of the purification were performed at $4^{\circ} \mathrm{C}$ unless otherwise noted. Liver microsomes $(2 \mathrm{mg} / \mathrm{ml}$ of protein in storage buffer [25]; $1,650 \mathrm{mg}$ of total protein, $880 \mathrm{nmol}$ of cytochrome P-450) prepared from specimen 8 were solubilized by the dropwise addition of a $20 \%$ (wt/vol) solution of cholate (recrystallized two times) to a final concentration of $0.6 \%$. The insoluble material was removed by centrifugation at $105,000 \mathrm{~g}$ for $1 \mathrm{~h}$. The resulting supernatant ( $675 \mathrm{nmol}$ of cytochrome P-450) was divided in half and each portion was applied to one of two identical
aminooctylamino-Sepharose 4B columns $(2.6 \times 37 \mathrm{~cm})$ prepared as previously described (25) and equilibrated in $100 \mathrm{mM}$ potassium phosphate buffer (pH 7.25) containing $1 \mathrm{mM}$ EDTA, 20\% glycerol, and $0.6 \%$ cholate. The columns were each washed with 5 column volumes of equilibration buffer containing $0.42 \%$ cholate. Hemoprotein was then eluted with equilibration buffer containing $0.33 \%$ cholate and 0.06\% Tergitol NP-10 (Sigma Chemical Co., St. Louis, MO).

The fractions from each column that contained hemoproteins comprised a narrow peak. The two peaks were combined and were concentrated to $\sim 50 \mathrm{ml}$ by ultrafiltration in an Amicon cell equipped with a PM30 filter. The concentrated hemoprotein solution was dialyzed against 1 liter of buffer $\mathrm{A}(5 \mathrm{mM}$ potassium phosphate, $\mathrm{pH} 7.7$, $0.1 \mathrm{mM}$ EDTA, $20 \%$ glycerol, $0.1 \%$ Tergitol NP-10, and $0.2 \%$ cholate) for $72 \mathrm{~h}$ with five changes. The dialyzed material was stirred at room temperature for $30 \mathrm{~min}$ and then applied at a rate of $1 \mathrm{ml} / \mathrm{min}$ to a DEAE (Whatman Chemical Separations, Inc., Clifton, NJ) column series (DE51 [1.6 $\times 7 \mathrm{~cm}]$, DE52 [1.6 $\times 15 \mathrm{~cm}]$, and DE53 [1.6 $\times 25$

Table I. Patient History and Immunoquantitation of Hepatic $H L x, H L d, H L p$, and $H L j$

\begin{tabular}{|c|c|c|c|c|c|c|c|c|}
\hline $\begin{array}{l}\text { Patient } \\
\text { no. }\end{array}$ & HLX & HLd & HLp & $\mathbf{H L j}$ & Gender & Age & Source* & Medications \\
\hline 1 & 173 & 67 & 288 & NA & $\mathbf{M}$ & - & D & Unknown \\
\hline 2 & 214 & 42 & 275 & 265 & $\mathbf{M}$ & 69 & $\mathbf{L}$ & $\begin{array}{l}\text { Erythromycin-base } \\
\text { Neomycin }\end{array}$ \\
\hline 3 & 69 & 71 & 150 & 412 & $\mathbf{M}$ & 27 & D & Ethanol $(0.22 \%)$ \\
\hline 4 & 158 & 66 & 650 & 188 & $\mathbf{F}$ & 33 & $\mathrm{D}$ & $\begin{array}{l}\text { Dexamethasone } \\
\text { Phenobarbital } \\
\text { Diphenylhydantoin }\end{array}$ \\
\hline 6 & 59 & 84 & 200 & 165 & $\mathbf{M}$ & 26 & D & $\begin{array}{l}\text { Hydrocortisone } \\
\text { Cimetidine }\end{array}$ \\
\hline 7 & 57 & 55 & 175 & 100 & $\mathbf{F}$ & 48 & $\mathbf{L}$ & None \\
\hline 8 & 270 & 45 & 563 & 318 & $\mathbf{M}$ & 52 & D & $\begin{array}{l}\text { Dexamethasone } \\
\text { Phenobarbital } \\
\text { Diphenylhydantoin }\end{array}$ \\
\hline 9 & 86 & 85 & 313 & 352 & $\mathbf{M}$ & 36 & D & $\begin{array}{l}\text { Dexamethasone } \\
\text { Diphenylhydantoin } \\
\text { Amobarbital }\end{array}$ \\
\hline 10 & 108 & 98 & 225 & 235 & $\mathbf{F}$ & 36 & $\mathbf{L}$ & None \\
\hline 11 & 149 & 77 & 525 & 353 & $\mathbf{F}$ & 38 & D & $\begin{array}{l}\text { Dexamethasone } \\
\text { Diphenylhydantoin } \\
\text { Furosemide } \\
\text { Sulfamethoxazole } \\
\text { Trimethoprim } \\
\text { Gentamycin }\end{array}$ \\
\hline 12 & 151 & 33 & 100 & 158 & $\mathbf{M}$ & 46 & $\mathbf{L}$ & None \\
\hline 13 & 69 & 11 & 763 & BD & $\mathbf{M}$ & 47 & $\mathbf{L}$ & Triacetyloleandomycin \\
\hline 14 & 100 & 100 & 100 & 100 & $\mathbf{M}$ & 50 & $\mathbf{L}$ & Flurazepam \\
\hline 16 & 69 & 42 & 179 & 159 & $\mathbf{F}$ & 45 & D & None \\
\hline 17 & 105 & 6 & 116 & 565 & $\mathbf{M}$ & 56 & D & $\begin{array}{l}\text { Ethanol }(0.30 \%) \\
\text { Allopurinol }\end{array}$ \\
\hline 18 & 108 & 105 & 233 & 247 & $\mathbf{M}$ & 26 & D & None \\
\hline 19 & 69 & 152 & 106 & 118 & $\mathbf{M}$ & 69 & $\mathbf{L}$ & None \\
\hline 20 & 133 & 23 & 309 & 160 & $\mathbf{F}$ & 51 & $\mathbf{L}$ & Erythromycin base \\
\hline 21 & 70 & 15 & 163 & 182 & $\mathbf{F}$ & 41 & D & Hydrochlorothiazide \\
\hline 22 & 87 & 14 & 167 & 588 & $\mathbf{F}$ & 43 & $\mathbf{L}$ & $\begin{array}{l}\text { Dexamethasone } \\
\text { Isoniazid }\end{array}$ \\
\hline 23 & 104 & 64 & 113 & 194 & $\mathbf{M}$ & 47 & $\mathbf{L}$ & None \\
\hline
\end{tabular}

Immunoquantitation of the human liver cytochromes P-450 were performed as described in Methods with the densitometric value obtained for specimen 14 arbitrarily set as $100 \%$. * Sources of liver specimens were patients undergoing hepatic lobectomy (L) or brain-dead renal transplant donors (D). BD, below limit of detection. NA, not available for study. 
$\mathrm{cm}]$ ) equilibrated at room temperature with 1 liter of buffer $\mathrm{A}$. The columns were washed with $300 \mathrm{ml}$ of buffer A followed by $500 \mathrm{ml}$ of buffer B ( $5 \mathrm{mM}$ potassium phosphate, $\mathrm{pH} 7.7,0.1 \mathrm{mM}$ EDTA, 20\% glycerol, $0.2 \%$ Tergitol NP-10, and $0.5 \%$ cholate). Then a $600-\mathrm{ml}$ 0-to-250-mM NaCl gradient in buffer B was applied to the column and the first peak fractions containing $417 \mathrm{~nm}$ absorbing material were combined.

The pooled fractions were dialyzed against 1 liter of buffer $\mathrm{C}(5 \mathrm{mM}$ potassium phosphate, pH 6.5, 20\% glycerol, $0.1 \mathrm{mM}$ EDTA, and $0.2 \%$ Tergitol NP-10) with three changes over $48 \mathrm{~h}$ and then applied at a rate of $1 \mathrm{ml} / \mathrm{min}$ to a CM52 (Whatman Chemical Separations, Inc.) column $(1.6 \times 30 \mathrm{~cm})$ equilibrated in buffer $C$. Bound hemoprotein was eluted by application of a $500-\mathrm{ml} 0$-to- $150-\mathrm{mM} \mathrm{NaCl}$ gradient in buffer $C$. Two peaks of $417 \mathrm{~nm}$ absorbing material were eluted. Those fractions in the second peak that contained only one protein, termed HLx, (as visualized by silver stained sodium dodecyl sulfate [SDS]polyacrylamide gels [10\%] [26]) were combined. Cytochrome P-450 HLx was concentrated and detergent was removed through the use of a small hydroxylapatite (Bio-Rad Laboratories, Richmond, CA) column (10).

Preparation of murine monoclonal antibodies. Five virus-free female Balb/c mice (15-18 g; Charles River Breeding Laboratories, Wilmington, MA) each received an intraperitoneal injection of $200 \mu \mathrm{l}$ containing $50 \mu \mathrm{g}$ of purified HLx in $50 \mathrm{mM}$ potassium phosphate $(\mathrm{pH}$ 7.5) buffer containing $50 \mathrm{mM}$ EDTA and $20 \%$ glycerol combined with an equal volume of Freund's complete adjuvant. After $21 \mathrm{~d}$, a second injection of $20 \mu \mathrm{g}$ of $\mathrm{HLx}$ was given. $6 \mathrm{~d}$ later serum samples from the mice were pooled and assayed for the presence of specific antibody by an enzyme-linked immunosorbent assay (ELISA). A final intraveneous injection of $20 \mu \mathrm{g}$ of $\mathrm{HLx}$ was given $3 \mathrm{~d}$ before surgery. Spleen cells were harvested from one immunized mouse and were fused with P3-X63-Ag multiple myeloma cells. The resulting hybridoma clones were expanded in vitro. Limiting dilutions were made to isolate individual clones. These were tested for specific antibody production by ELISA and, after the clones had expanded, the cells were injected into female Balb/c mice $\left(5 \times 10^{6}\right.$ cells per mouse $)$ that had been primed with an intraperitoneal injection of pristane $(0.5 \mathrm{ml}) 2 \mathrm{wk}$ previously. The ascitic fluid that appeared was collected 9-14 $\mathrm{d}$ later, clarified by centrifugation, and stored at $-80^{\circ} \mathrm{C}$.

Immunochemical assays. Immunoblot analyses were performed as previously described (9). Briefly, microsomal proteins separated by electrophoresis in $0.15 \times 10 \mathrm{~cm}$ SDS-polyacrylamide gels (10\%) (26) were transferred to nitrocellulose sheets electrophoretically. The sheets were incubated overnight in phosphate-buffered saline containing $3 \%$ bovine serum albumin and $10 \%$ calf serum and then were reacted sequentially with murine monoclonal anti-HLx, peroxidase-conjugated rabbit anti-mouse IgG (ICN ImmunoBiologicals, Lisle, IL), and, finally, 3,3'-diaminobenzidine tetrahydrochloride in hydrogen peroxide $(0.006 \%)$. In the experiments where a rabbit IgG was used as the primary antibody, the second antibody was goat anti-rabbit IgG (ICN) and this was followed by peroxidase rabbit anti-peroxidase (ICN). The density and total area of the stained bands were determined using a scanning densitometer (Carl Zeiss, Inc., Thornwood, NY) (9). In preliminary analyses, dilutions of microsomes isolated from patient 14 produced integrated optical density values directly proportional to the amount of microsomal protein applied to the gel.

Noncompetitive ELISA was performed as described (21) with all proteins coated on 96-well microtiter plates at $0.2 \mu \mathrm{g} / \mathrm{ml}$. All of the primary antibodies were purified IgG fractions of hyperimmune sera from rabbits except anti-P-450a, which was raised in sheep. The polyclonal antibodies were made monospecific for the antigens of immunization by previously reported procedures $(21,27,28)$.

\section{Results and Discussion}

We used the approach of sequential column chromatography of cholate-solubilized human liver microsomes on amino-
octylamino-Sepharose 4B, DEAE-cellulose, and CM-cellulose to purify a prominant isozyme of cytochrome $\mathrm{P}-450$ from a single human liver. The purified protein, termed HLx, appeared homogeneous as judged by electrophoresis in SDSpolyacrylamide gels stained with silver (Fig. 1). The specific heme content of the HLx preparation was $9.5 \mathrm{nmol}$ of $\mathrm{CO}$ binding hemoprotein per $\mathrm{mg}$ of protein, representing a final yield of $1.9 \%$ of the starting material. The apparent molecular weight of HLx was $50.5 \mathrm{kD}$, a value slightly less than that determined for human liver cytochrome HLp (Fig. 1) (9). Absolute and $\mathrm{CO}$-reduced spectral analyses disclosed, respectively, that HLx exists predominantly in the low-spin state and has a Soret wavelength maximum at $452 \mathrm{~nm}$ (not shown).

Amino-terminal amino acid sequence analysis is useful for characterizing even closely related forms of cytochrome P-450 $(6,14)$, so we submitted HLx for sequence analysis by automated Edman degradation (Table II). The 19-amino acid sequence we obtained for HLx revealed no significant homology with that previously determined for several other human cytochromes P-450 including HLp (9), HLd (11), and HLj (12) (Table II). However, the $\mathrm{NH}_{2}$-terminal amino acid sequence of HLx was homologous in 13 of the identified 18 residues with that reported for an isozyme of human cytochrome P-450 identified by its ability to catalyze the metabolism of mephenytoin (P-450MP) (29) (Table II). Moreover, when compared with rat cytochromes P-450 $(6,14)$, HLx shares high homology with the immunochemically related cytochromes P-450f, $\mathrm{P}-450 \mathrm{~g}, \mathrm{P}-450 \mathrm{~h}$, and P-450i (14), all found in untreated animals (Table II). Consistent with this similarity is the homology at 12 of the 19 identified amino acids between HLx and rabbit P-450 LM1 (Table II), a cytochrome that appears to be related to rat cytochrome $\mathrm{P}-450 \mathrm{~g}(30)$. Finally, this $\mathrm{NH}_{2}$-terminal amino acid sequence for HLx was found to be much less similar to that reported (6) for rat cytochromes P-450a (5/19), P-450b (8/19), P-450c (3/19), P-450d (2/19), P-450e (8/19), P-450k (6/19), and P-450j (2/19).

Upon finding HLx to be most related to the family of rat cytochromes $\mathrm{P}-450 \mathrm{f}-\mathrm{i}$, we performed detailed comparisons of the immunoreactivity of purified HLx with specific anti-rat

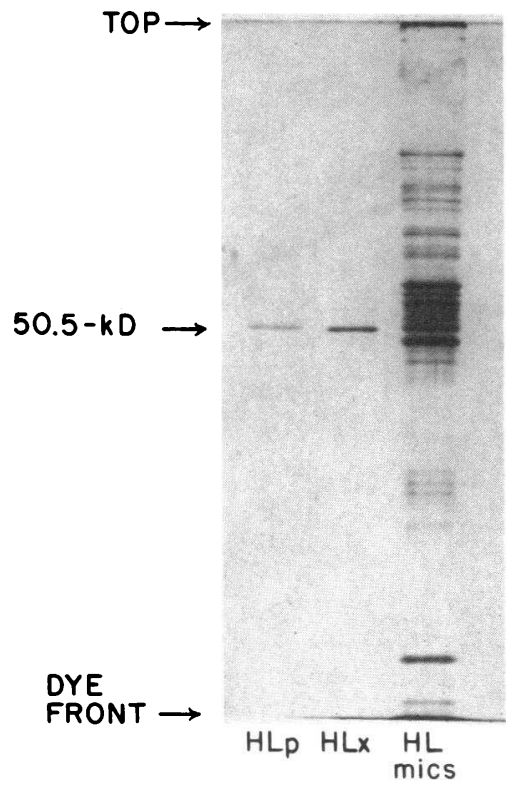

Figure 1. Electrophoretic profile of human liver microsomes and purified cytochromes HLx and HL̀p. Liver microsomes $(5 \mu \mathrm{g})$ and purified proteins $(1 \mu \mathrm{g}$ each) were prepared, subjected to electrophoresis in a SDS-polyacrylamide gel $(10 \%)$, and visualized by silver staining, as described in Methods. 
Table II. $\mathrm{NH}_{2}$-Terminal Amino Acid Sequences of HLx and Other Cytochromes P-450

\begin{tabular}{|c|c|c|c|c|c|c|c|c|c|c|c|c|c|c|c|c|c|c|c|c|c|c|}
\hline \multirow[b]{2}{*}{ Species } & \multirow[b]{2}{*}{ Isozyme } & \multicolumn{20}{|c|}{ Residues identified } & \multirow{2}{*}{$\begin{array}{l}\text { Comparisons } \\
\text { to HLx }\end{array}$} \\
\hline & & 1 & 2 & 3 & 4 & 5 & 6 & 7 & 8 & 9 & 10 & 11 & 12 & 13 & 14 & 15 & 16 & 17 & 18 & 19 & 20 & \\
\hline \multirow[t]{5}{*}{ Human } & HLx & $\mathbf{M}$ & $\mathbf{E}$ & $\mathbf{P}$ & $\mathbf{F}$ & V & $\mathbf{V}$ & $\mathbf{L}$ & $\mathbf{V}$ & $\mathbf{L}$ & $?$ & $\mathbf{L}$ & $\mathbf{S}$ & $\mathbf{F}$ & $\mathbf{M}$ & $\mathrm{L}$ & $\mathbf{L}$ & $\mathbf{F}$ & $\mathbf{S}$ & $\mathbf{L}$ & W & $19 / 19$ \\
\hline & HLp & (M) & $\mathbf{A}$ & $\mathbf{L}$ & I & $\mathbf{P}$ & D & $\underline{\mathbf{L}}$ & A & $\mathbf{M}$ & $\mathbf{Q}$ & $\mathbf{T}$ & W & $\mathbf{L}$ & $\mathbf{L}$ & $\underline{\mathbf{L}}$ & $\mathbf{A}$ & $\mathbf{V}$ & $\underline{\mathbf{S}}$ & $\underline{\mathbf{L}}$ & $\mathbf{V}$ & $5 / 19$ \\
\hline & $\mathrm{HLj}$ & - & $\mathbf{A}$ & A & $\mathbf{L}$ & G & $\underline{\mathbf{V}}$ & $\mathrm{T}$ & $\underline{\mathbf{V}}$ & A & $\mathbf{L}$ & $\underline{\mathbf{L}}$ & V & W & A & A & $\mathbf{F}$ & $\mathbf{L}$ & $\mathbf{L}$ & $\underline{\mathbf{L}}$ & - & $4 / 17$ \\
\hline & HLd & - & $\mathbf{A}$ & $\mathbf{L}$ & $\mathbf{S}$ & Q & $\mathbf{S}$ & V & $\mathbf{P}$ & $\mathbf{F}$ & $\mathbf{S}$ & A & $\mathrm{T}$ & $\mathrm{E}$ & $\mathbf{L}$ & $\underline{\mathbf{L}}$ & $\underline{\mathrm{L}}$ & A & $\underline{\mathbf{S}}$ & $\mathbf{A}$ & - & $3 / 17$ \\
\hline & MP & $\underline{\mathbf{M}}$ & D & $\mathbf{S}$ & $\mathrm{L}$ & $\underline{\mathbf{V}}$ & $\underline{\mathbf{V}}$ & $\underline{\mathbf{L}}$ & $\underline{\mathbf{V}}$ & $\underline{\mathbf{L}}$ & $?$ & $\underline{\mathbf{L}}$ & $\underline{\mathbf{S}}$ & $?$ & $\mathbf{L}$ & $\underline{\mathbf{L}}$ & $\underline{\mathrm{L}}$ & $\mathrm{L}$ & $\underline{\mathbf{S}}$ & $\underline{\mathbf{L}}$ & $\underline{\mathbf{w}}$ & $13 / 18$ \\
\hline \multirow[t]{4}{*}{ Rat } & $P-450 f$ & $\underline{\mathbf{M}}$ & D & $\mathrm{L}$ & V & $\mathrm{T}$ & $\mathrm{F}$ & $\underline{\mathbf{L}}$ & $\underline{\mathbf{V}}$ & $\underline{\mathbf{L}}$ & $\mathbf{T}$ & $\underline{\mathbf{L}}$ & $\underline{\mathbf{S}}$ & $\mathbf{S}$ & $\mathbf{L}$ & I & $\underline{\mathbf{L}}$ & $\mathbf{L}$ & $\underline{\mathbf{S}}$ & $\underline{\mathbf{L}}$ & $\underline{\mathbf{w}}$ & $10 / 19$ \\
\hline & P-450g & $\underline{\mathbf{M}}$ & D & $\underline{\mathbf{P}}$ & $\mathbf{V}$ & $\underline{\mathbf{V}}$ & $\underline{\mathbf{V}}$ & $\underline{\mathbf{L}}$ & $\mathbf{L}$ & $\underline{\mathrm{L}}$ & $\mathbf{S}$ & $\underline{\mathbf{L}}$ & $F$ & $\underline{\mathbf{F}}$ & $\mathbf{L}$ & $\underline{\mathrm{L}}$ & - & - & - & - & - & $9 / 14$ \\
\hline & $\mathrm{P}-450 \mathrm{~h}$ & $\underline{\overline{\mathbf{M}}}$ & D & $\overline{\mathbf{P}}$ & V & $\bar{L}$ & $\underline{\mathbf{V}}$ & $\underline{\mathbf{L}}$ & $\underline{\mathbf{V}}$ & $\underline{\mathrm{L}}$ & $\mathrm{T}$ & $\underline{\mathbf{L}}$ & $\underline{\mathbf{S}}$ & $\bar{S}$ & $\mathbf{L}$ & $\underline{\mathrm{L}}$ & $\underline{\mathrm{L}}$ & $\mathbf{L}$ & $\underline{\mathbf{S}}$ & $\underline{L}$ & $\underline{\mathbf{w}}$ & $13 / 19$ \\
\hline & $P-450 \mathrm{i}$ & $\underline{\mathbf{M}}$ & D & $\underline{\mathbf{P}}$ & $\underline{F}$ & $\underline{\mathbf{V}}$ & $\underline{\mathbf{v}}$ & $\underline{\mathbf{L}}$ & $\underline{\mathbf{V}}$ & $\underline{\mathbf{L}}$ & $\mathbf{S}$ & $\underline{\mathbf{L}}$ & $\underline{\mathbf{S}}$ & $\underline{\mathbf{F}}$ & $\mathbf{L}$ & $\underline{L}$ & $\underline{\mathrm{L}}$ & L & $\mathbf{Y}$ & $?$ & $\underline{\mathbf{w}}$ & $14 / 18$ \\
\hline Rabbit & LM1 & $\underline{\overline{\mathbf{M}}}$ & D & $\underline{\mathbf{P}}$ & $\mathbf{V}$ & $\underline{\mathbf{V}}$ & $\underline{\mathbf{V}}$ & $\underline{\mathbf{L}}$ & $\underline{\mathbf{V}}$ & $\underline{\mathbf{L}}$ & $\mathbf{G}$ & $\underline{\mathbf{L}}$ & $\mathrm{C}$ & $\mathrm{C}$ & $\mathbf{L}$ & $\underline{\mathbf{L}}$ & $\underline{\mathbf{L}}$ & $\mathbf{L}$ & $\underline{\mathbf{S}}$ & I & $\underline{\mathbf{W}}$ & $12 / 19$ \\
\hline
\end{tabular}

The $\mathrm{NH}_{2}$-terminal amino acid sequence of $\mathrm{HLx}$ was determined by automated Edman degradation using a gas-phase sequencer (9). Yield on the $\mathrm{NH}_{2}$-terminal Met was $76 \mathrm{pmol}$ (15\% yield).

cytochrome P-450 antibodies as determined by ELISA and immunoblot analyses. Cytochrome HLx gave a significant positive ELISA reaction with a monospecific polyclonal anti$\mathrm{P}-450 \mathrm{~g}$ IgG that does not react with other rat cytochrome $\mathrm{P}-450$ isozymes (21) (Table III). In contrast $\mathrm{HLx}$ was not recognized by monospecific antibodies to P-450f, P-450a, P-450b, P-450c, P-450d,or P-450i (Table III). In addition, none of five monoclonal antibodies specific for cytochrome P-450h (31) gave a significant reaction with HLx in the ELISA (data not shown). Moreover, immunoblots of purified HLx developed with antibody preparations monospecific for cytochrome $\mathrm{P}-450$ f, $\mathrm{P}-450 \mathrm{i}$, or $\mathrm{P}-450 \mathrm{~g}$ demonstrated that only the last antibody, anti-P-450g, recognized HLx (Fig. $2 A$ ). However, immunoblots of HLx developed with polyclonal antibodies directed against cytochrome $\mathrm{P}-450 \mathrm{f}, \mathrm{P}-450 \mathrm{~g}$, or $\mathrm{P}-450 \mathrm{i}$ that had not been absorbed to render them monospecific each reacted strongly with HLx (Fig. $2 B$ ). These results indicate that HLx is related not only to P-450g but also to P-450f and $\mathrm{P}-450 \mathrm{i}$. Thus, the results from these immunochemical comparisons indicate that HLx is immunochemically most closely related to $\mathrm{P}-450 \mathrm{~g}$.

Next, we examined interindividual differences among 21 human liver specimens for the amounts of HLx protein. We prepared a murine monoclonal antibody against purified HLx

Table III. Reactivity of Purified Human Cytochrome HLx with Polyclonal Antibodies Made against Several Rat Cytochrome P-450 Isozymes in an ELISA

\begin{tabular}{llll}
\hline & \multicolumn{2}{l}{ Absorbance at 490 $\mathrm{nm}$} & \\
\cline { 2 - 3 } Antibody & $\begin{array}{l}\text { Homologous } \\
\text { rat protein }\end{array}$ & HLx & $\begin{array}{l}\text { HLx } \% \\
\text { reactivity }\end{array}$ \\
\hline Anti-P-450a & 0.92 & 0.00 & ND \\
Anti-P-450b & 1.15 & 0.01 & $<2 \%$ \\
Anti-P-450c & 1.88 & 0.00 & ND \\
Anti-P-450d & 0.74 & 0.00 & ND \\
Anti-P-450f & 1.62 & 0.00 & ND \\
Anti-P-450g & 1.31 & 0.25 & 19 \\
Anti-P-450i & 1.23 & 0.00 & ND \\
\hline
\end{tabular}

Conditions for the noncompetitive ELISA and the sources of the antibodies are given in Methods. Antibodies used are monospecific for the antigen of immunization, except anti-P-450b, which also recognizes cytochrome P-450e (32). for immunoquantitation analyses (Fig. 3). This monoclonal antibody gave a negative reaction when tested by immunoblot analysis or ELISA with any of 12 purified rat cytochromes P-450 (P-450a-k and P-450p, data not shown). Analyses of 21 human liver microsomal samples immunoblots developed with monoclonal anti-HLx revealed, in each instance, a single well-defined band having the mobility of HLx (data not shown). We made quantitative measurements of $\mathrm{HLx}$ by scanning densitometry of immunoblots developed with the monoclonal anti-HLx IgG (Table I), the results being expressed relative to the value for patient 14 (arbitrarily set to $100 \%$ ). There was a 4.7 -fold range in the level of liver microsomal immunoreactive HLx (Table I) among the 21 samples. This range is less than that determined in the same samples for cytochromes HLj (5.9-fold), HLp (7.6-fold), or HLd (25-fold) (Table I). The values for the concentration of immunoreactive HLx gave no significant correlation with the age, gender, or history of medications for the patients (Table I). However, as demonstrated in previous studies, $\mathrm{HLj}$ levels were significantly elevated in patients receiving isoniazid or ethanol (12), and HLp levels were significantly elevated in patients receiving dexamethansone or triacetyloleandomycin (9). In addition, the widely varying HLd levels did not segregate with any of the parameters examined (11). Furthermore, the amounts of HLx immunoreactive protein were unrelated to that for three other human liver cytochromes P-450, HLd (11), HLj (12), and HLp (9) (Table I). On inspection of this HLx immunoquantitation data, it is evident that the seven highest values $(>133)$ represent a population distinct from the remaining 14 low values. Statistical analysis of this data indicated that the distribution of HLx in these patients is at least bimodal, with the break occurring as indicated above (Ward's minimum variance cluster analysis [33]). Although additional samples are needed to confirm the bimodal distribution of HLx, the present data suggest that there may be a polymorphism among humans for high and low expression of immunoreactive HLx protein. Whereas this conclusion is unprecedented for other human cytochromes P-450, the levels of P-450g in Long Evans rats (21) and LM1 in New Zealand White rabbits (34) are at least bimodally distributed. For example, among individual Long Evans rats there is a 50 -fold difference in P-450g levels (21) and among New Zealand White rabbits there is a 10 -fold difference in LM1 levels (34). However, our observations do not 
A MONOSPECIFIC IgGs
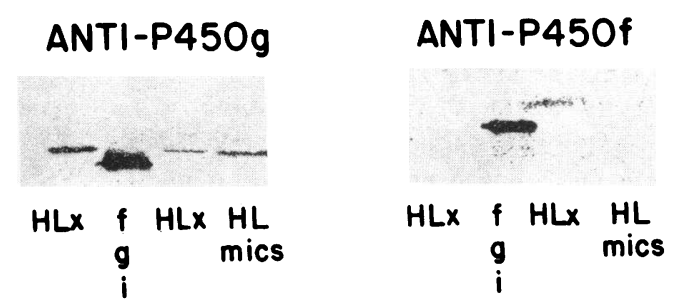

\section{B POLYSPECIFIC IgGS}
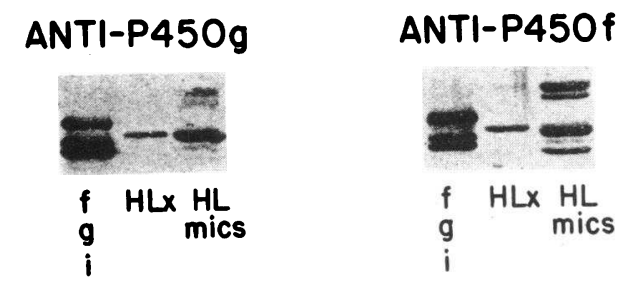

eliminate the possibility that the bimodal distribution of $\mathrm{HLg}$ levels reflect the influences of yet to be identified environmental factors.

It was possible that the function of HLx might resemble that of either rat cytochrome $\mathrm{P}-450 \mathrm{~g}$ or rabbit cytochrome P-450 LM1. For example, LM1 catalyzes the 21-hydroxylation of progesterone in rabbits resulting in formation of deoxycorticosterone (17). However, human liver microsomes do not catalyze progesterone hydroxylation at the 21 position (35). In a reconstituted system consisting of purified HLx, optimal phospholipid, and excess purified rat NADPH-cytochrome P-450 reductase, no detectable metabolism of progesterone was observed, including hydroxylation at the 21 position. However, very low but detectable (nmol product/min per nmol HLx) metabolism by HLx was observed with benzo(a)pyrene (0.15), 7-ethoxycoumarin (0.6), and testosterone $(0.3,16 \alpha$-hydroxytestosterone). In addition, HLx actively metabolized benzphetamine (9.7). Therefore, although HLx is catalytically active, its metabolism of progesterone clearly differs from rabbit LM1 (17) and rat P-450g (36). Such a loss of correspondence in substrate specificity of structurally related cytochromes has been noted previously for other interspecies comparisons. For example, cytochrome P-450p metabolizes mephenytoin in the rat (37), whereas in humans this drug is oxidized not by its

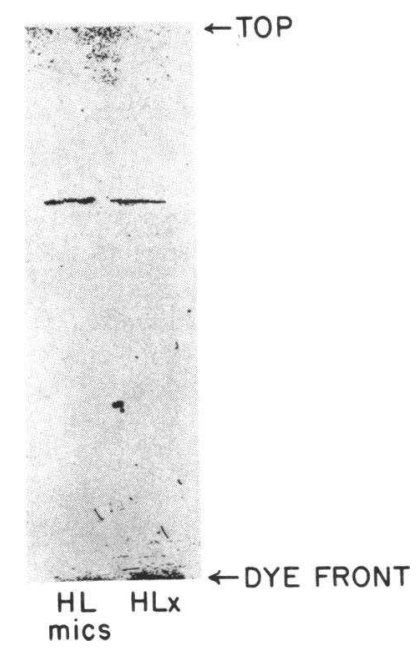

Figure 3. Immunoblot of human liver microsomes and purified cytochrome HLx developed with monoclonal anti-HLx. Human liver microsomes $(25 \mu \mathrm{g})$ isolated from patient 8 and cytochrome HLx $(0.5 \mu \mathrm{g})$ were immunoblotted as described in Methods using a murine monoclonal anti-HLx IgG.

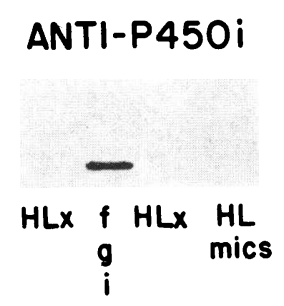

Figure 2. Immunoblots of human liver microsomes and cytochrome HLx and rat liver cytochromes P-450f, P-450g, and P-450i. Purified human liver cytochrome HLx $(0.2 \mu \mathrm{g}$, left; $0.05 \mu \mathrm{g}$, right) and rat liver cytochromes $\mathrm{P}-450 \mathrm{f}, \mathrm{P}-450 \mathrm{~g}$, and P-450i (0.2 $\mu \mathrm{g}$ each) and human liver microsomes isolated from patient $8(5 \mu \mathrm{g})$ were immunoblotted as described in Methods with $(A)$ antibodies rendered monospecific by immunoabsorption for rat liver cytochromes P-450g, P-450f, or P-450i or (B) antibodies against rat liver cytochromes $\mathrm{P}-450 \mathrm{~g}, \mathrm{P}-450 \mathrm{f}$, and P-450i before immunoabsorption.

ortholog HLp, but rather by P-450MP, a cytochrome structurally related to but clearly distinct from HLx.

Recently, a full-length complementary DNA (cDNA) clone to a human liver mRNA has been isolated with the use of an antibody probe to rabbit LM1 (38). The deduced $\mathrm{NH}_{2}-$ terminal amino acid sequence of the protein encoded by this cDNA (38) and that described here for HLx protein (Table II) match each other exactly. Analyses of human genomic DNA with this probe suggest that the encoded protein, probably HLx or a highly related isozyme, is a representative of a large multigene family (Robert H. Tukey, personal communication). This interpretation is supported by our finding multiple protein bands on immunoblots of human liver microsomes developed with antibodies that recognize rat cytochromes P-450f-i (Fig. 2 B). Based on comparisons of $\mathrm{NH}_{2}$-terminal amino acid sequences (Table II) and complete cDNA sequences (39; Robert H. Tukey, personal communication), we believe that HLx and P-450MP, a human liver mephenytoinmetabolizing isozyme (29), are structurally related members of the same gene family. A better understanding of the function and genetic control of this family of "uninducible" isozymes may help to explain clinically important interindividual differences in the physiologic and toxicologic processes dependent on the cytochromes P-450.

\section{Acknowledgments}

The authors wish to thank Lauren Cunningham for her excellent secretarial assistance.

This research was supported in part by grants from the National Institutes of Health (GM-37498 and AM-37261), the Virginia Environmental Endowment, Exxon Corporation, and the Virginia Center of Innovative Technology.

\section{References}

1. Conney, A. H. 1967. Pharmacological implications of microsomal enzyme induction. Pharmacol. Rev. 19:317-366.

2. Ryan, D. E., P. E. Thomas, L. M. Reik, and W. Levin. 1982. Purification, characterization and regulation of five rat hepatic microsomal cytochrome P-450 isozymes. Xenobiotica. 12:727-744.

3. Kalow, W. 1986. Genetics of drug transformation. Clin. Biochem. 19:76-82. 
4. Guengerich, F. P., L. M. Dislerath, P. E. B. Reilly, T. Wolff, T. Shimada, D. R. Umbenhauer, and M. V. Martin. 1986. Human-liver cytochromes P-450 involved in polymorphisms of drug oxidation. Xenobiotica. 16:367-378.

5. Okey, A. B., E. A. Roberts, P. A. Harper, and M. S. Denison. 1986. Induction of drug-metabolizing enzymes: mechanisms and consequences. Clin. Biochem. 19:132-141.

6. Black, S. D., and M. J. Coon. 1986. Comparative structures of P-450 cytochromes. In Cytochrome P-450. Structure, Mechanism and Biochemistry. P. R. Ortiz de Montellano, editor. Plenum Publishing Corp., New York. 161-216.

7. Adesnik, M., and M. Atchison. 1985. Genes for cytochrome P-450 and their regulation. CRC Crit. Rev. Biochem. 19:247-305.

8. Whitlock, J. P., Jr. 1986. The regulation of cytochrome P-450 gene expression. Annu. Rev. Pharmacol. Toxicol. 26:333-369.

9. Watkins, P. B., S. A. Wrighton, P. Maurel, E. G. Schuetz, G. Mendez-Picon, G. A. Parker, and P. S. Guzelian. 1985. Identification of an inducible form of cytochrome P-450 in human liver. Proc. Natl. Acad. Sci. USA. 82:6310-6314.

10. Wrighton, S. A., P. Maurel, E. G. Schuetz, P. B. Watkins, B. Young, and P. S. Guzelian. 1985. Identification of the cytochrome $\mathrm{P}-450$ induced by macrolide antibiotics in rat liver as the glucocorticoid responsive cytochrome P-450p. Biochemistry. 24:2171-2178.

11. Wrighton, S. A., C. Campanile, P. E. Thomas, S. L. Maines, P. B. Watkins, G. Parker, G. Mendez-Picon, M. Haniu, J. E. Shively, W. Levin, and P. S. Guzelian. 1986. Identification of a human liver cytochrome P-450 homologous to the major isosafrole-inducible cytochrome P-450 in the rat. Mol. Pharmacol. 29:405-410.

12. Wrighton, S. A., P. E. Thomas, D. T. Molowa, M. Haniu, J. E. Shively, S. L. Maines, P. B. Watkins, G. Parker, G. Mendez-Picon, W. Levin, and P. S. Guzelian. 1986. Characterization of ethanol-inducible human liver $N$-nitrosodimethylamine demethylase. Biochemistry. 25:6731-6735.

13. Ryan, D. E., S. Iida, A. W. Wood, P. E. Thomas, C. S. Lieber, and W. Levin. 1984. Characterization of three highly purified cytochromes P-450 from hepatic microsomes of adult male rats. J. Biol. Chem. 259:1239-1250.

14. Haniu, M., D. E. Ryan, S. Iida, C. S. Lieber, W. Levin, and J. E. Shively. 1984. $\mathrm{NH}_{2}$-terminal sequence analyses of four rat hepatic microsomal cytochromes P-450. Arch. Biochem. Biophys. 235:304311.

15. Kamataki, T., M. Maeda, Y. Yamazoe, T. Nagai, and R. Kato. 1983. Sex difference of cytochrome P-450 in the rat: purification, characterization, and quantitation of constitutive forms of cytochrome P-450 from liver microsomes of male and female rats. Arch. Biochem. Biophys. 255:758-770.

16. Waxman, D. J. 1984. Rat hepatic cytochrome P-450 isoenzyme 2c. J. Biol. Chem. 259:15481-15490.

17. Johnson, E. F., and G. E. Schwab. 1984. Constitutive forms of rabbit-liver microsomal cytochrome P-450: enzymatic diversity, polymorphism and allosteric regulation. Xenobiotica. 14:3-19.

18. Reubi, I., K. J. Griffin, J. L. Raucy, and E. F. Johnson. 1984. Three monoclonal antibodies to rabbit microsomal cytochrome P-450 1 recognize distinct epitopes that are shared to different degrees among other electrophoretic types of cytochrome P-450. J. Biol. Chem. 289:5887-5892.

19. Nebert, D. W. 1979. Multiple forms of inducible drug-metabolizing enzymes: a reasonable mechanism by which any organism can cope with adversity. Mol. Cell. Biochem. 27:27-46.

20. Gonzalez, F. J., S. Kimura, B.-J. Song, J. Pastewka, H. V. Gelboin, and J. P. Hardwick. 1986. Sequence of two related P-450 mRNAs transcriptionally increased during rat development. J. Biol. Chem. 251:10667-10672.

21. Bandiera, S., D. E. Ryan, W. Levin, and P. E. Thomas. 1986. Age- and sex-related expression of cytochromes P-450f and P-450g in rat liver. Arch. Biochem. Biophys. 248:658-676.
22. McClellan-Green, P., D. J. Waxman, M. Caveness, and J. A. Goldstein. 1987. Phenotypic differences in expression of cytochrome P-450g but not its mRNA in outbred male Sprague-Dawley rats. Arch. Biochem. Biophys. 253:13-25.

23. van der Hoeven, T. A., and M. J. Coon. 1974. Preparation and properties of partially purified cytochrome $\mathrm{P}-450$ and reduced nicotinamide adenine dinucleotide phosphate-cytochrome $P-450$ reductase from rabbit liver microsomes. J. Biol. Chem. 249:6302-6310.

24. Lowry, O. H., N. J. Rosenbrough, A. L. Farr, and R. J. Randall. 1951. Protein measurement with Folin phenol reagent. J. Biol. Chem. 193:265-275.

25. Wang, P. P., P. Beaune, L. S. Kaminsky, G. A. Dannan, F. F. Kadlubar, D. Larrey, and F. P. Guengerich. 1983. Purification and characterization of six cytochrome $\mathrm{P}-450$ isozymes from human liver microsomes. Biochemistry. 22:5375-5383.

26. Laemmli, V. K. 1970. Cleavage of structural proteins during the assembly of the head of bacteriophage 14. Nature (Lond.). 227:680-685.

27. Thomas, P. E., L. M. Reik, D. E. Ryan, and W. Levin. 1981. Regulation of three forms of cytochrome $\mathrm{P}-450$ and epoxide hydrolase in rat liver microsomes. Effects of age, sex and induction. J. Biol. Chem. 256:1044-1052.

28. Reik, L. M., W. Levin, D. E. Ryan, and P. E. Thomas. 1982. Immunochemical relatedness of rat hepatic microsomal cytochromes P-450c and P-450d. J. Biol. Chem. 257:3950-3957.

29. Shimada, T., K. S. Misono, and F. P. Guengerich. 1986. Human liver microsomal cytochrome P-450 mephenytoin 4-hydroxylase, a prototype of genetic polymorphism in oxidative drug metabolism. Purification and characterization of two similar forms involved in the reaction. J. Biol. Chem. 261:909-921.

30. Tukey, R. H., S. Okino, H. Barnes, K. J. Griffin, and E. F. Johnson. 1985. Multiple gene-like sequences related to the rabbit hepatic progesterone 21-hydroxylase cytochrome P-450 1. J. Biol. Chem. 260:13347-13354.

31. Maines, S. L., L. M. Reik, D. E. Ryan, W. Levin, and P. E. Thomas. 1986. Monoclonal antibodies (MAb) to rat liver cytochrome P-450h. Fed. Proc. 45:1510.

32. Ryan, D. E., P. E. Thomas, and W. Levin. 1982. Purification and characterization of a minor form of hepatic microsomal cytochrome P-450 from rats treated with polychlorinated biphenyls. Arch. Biochem. Biophys. 216:272-288.

33. SAS User's Guide. 1985. Statistics. 5th ed. SAS Institute Inc., Cary, NC.

34. Dieter, H. H., U. Muller-Eberhard, and E. F. Johnson. 1982. Rabbit hepatic progesterone 21-hydroxylase exhibits a bimodal distribution of activity. Science Wash. DC). 217:741-743.

35. Winkel, C. A., E. R. Simpson, L. Milewich, and P. C. MacDonald. 1980. Deoxycorticosterone biosynthesis in human kidney: potential for formation of a potent mineralocorticosteroid in its site of action. Proc. Natl. Acad. Sci. USA. 77:77069-7073.

36. Swinney, D. C., D. E. Ryan, P. E. Thomas, and W. Levin. 1986. Quantitative HPLC analysis of progesterone metabolism by $11 \mathrm{cy}-$ tochrome P-450 isozymes purified from rat liver microsomes. Fed. Proc. 45:1664.

37. Shimada, T., and F. P. Guengerich. 1985. Participation of a rat liver cytochrome P-450 induced by pregnenolone-16 $\alpha$-carbonitrile and other compounds in the 4-hydroxylation of mephenytoin. Mol. Pharmacol. 28:215-219.

38. Tukey, R. H., L. C. Quattrochi, U. R. Pendurthi, and S. T. Okino. 1986. Identification of a human cytochrome $P-450$ highly related to rabbit liver progesterone 21-hydroxylase P-450. Fed. Proc. 45:1663.

39. Umbenhauer, D. R., M. V. Martin, R. S. Lloyd, and F. P. Guengerich. 1987. Cloning and sequence determination of a complementary DNA relate to human liver microsomal cytochrome P-450 S-mephenytoin 4-hydroxylase. Biochemistry. 26:1094-1099. 